\title{
Endoscopic stenting of the biliary tract and pancreatic duct
}

\author{
K HuibregtSe, MD, S RiVERA-MACMURRAy, MD
}

K HUIBREGTSE, S RIVERA-MACMURRAY. Endoscopic stenting of the biliary tract and pancreatic duct. Can J Gastroenterol 1993;7(1):15-22. Biliary and pancreatic drainage by endoscopic insertion of endoprostheses has become routine treatment for patients with malignant obstructions. This method is particularly indicated for patients with irresectable tumour or contraindications for surgery. However, accumulating data suggest this method is superior even to surgical palliative procedures. Endoscopic treatment of benign biliary and pancreatic strictures is more controversial and further studies are needed to establish its place among the other nonsurgical and surgical treatment modalities. A survey of possible indications, success rates and complication rates are discussed and compared with other treatment options.

Key Words: Bile duct strictures, Biliary drainage, Endoscopic retrograde cholangiopancreatography, Obstructive jaundice

\section{Moulage endoscopique des voies biliaires et du canal pancréatique}

RÉSUMÉ: Le drainage biliaire et pancréatique par insertion endoscopique d'endoprothèses est devenu un traitement de routine chez les patients atteints d'obstruction maligne. Cette méthode est particulièrement indiquée chez les patients porteurs de tumeurs impossibles à réséquer ou chez qui il est contreindiqué d'intervenir chirurgicalement. Cependant, les données recueillies suggèrent que cette méthode serait même supérieure aux interventions chirurgicales palliatives. Le traitement endoscopique des rétrécissements bénins des voies biliaires et pancréatiques est plus controversé et d'autres études sont requises pour évaluer son rôle parmi les autres modalités thérapeutiques chirurgicales et nonchirurgicales. On procède à un survol des indications possibles, des taux de réussite et des taux de complication propres à différentes options thérapeutiques.

S INCE THE INITIAL DESCRIPTION BY Soehendra in 1980 of endoscopic insertion of a transpapillary stent (1), the procedure has gained wide acceptance and multiple applications (2). Indications, complications and success rates have been studied. Endoscopic stent placement in benign and malig- nant biliary lesions, and management of pancreatic disorders are discussed.

\section{TECHNIQUE OF STENT INSERTION}

The authors use an endoscope with a large $4.2 \mathrm{~mm}$ instrumentation channel to start the procedure, although others prefer to use a diagnostic endoscope with a 2.7 or $3.2 \mathrm{~mm}$ channel initially. Cannulation may be difficult because of tumour compression, displacement or fixation. On occasion a precut papillotomy may be needed to unroof the papilla and to gain access to the bile duct. After routine endoscopic retrograde cholangiopancreatography (ERCP) a 6 to $8 \mathrm{~mm}$ sphincterotomy is performed to facilitate stent insertion and subsequent exchanges. Cytology brushings are done at this point. Then a Teflon catheter containing an atraumatic flexible tip guidewire is inserted into the common bile duct up to the structure. The guidewire is manipulated across it by movements of the wire, the catheter and the endoscope as needed under fluoroscopy. Forceful pushing should be avoided so that false passages are not created.

Once the rigid part of the guidewire is well above the stenosis, the Teflon catheter is pushed above the stricture also. The stent is loaded on to the Teflon catheter and wire assembly and advanced to the tip of the endoscope with the pusher tube. The elevator bridge is opened when the stent is felt to be adjacent to it. The whole assembly (guidewire, Teflon catheter, stent and pusher tube) is then moved forward by advancing the pusher tube. The assistant secures and withdraws the guiding catheter/wire slightly as the endoscopist advances the pusher tube. The endoprosthesis is moved up the duct in a stepwise fashion as the endoscopist opens and closes the elevator bridge in coordination with elevation of the en- 

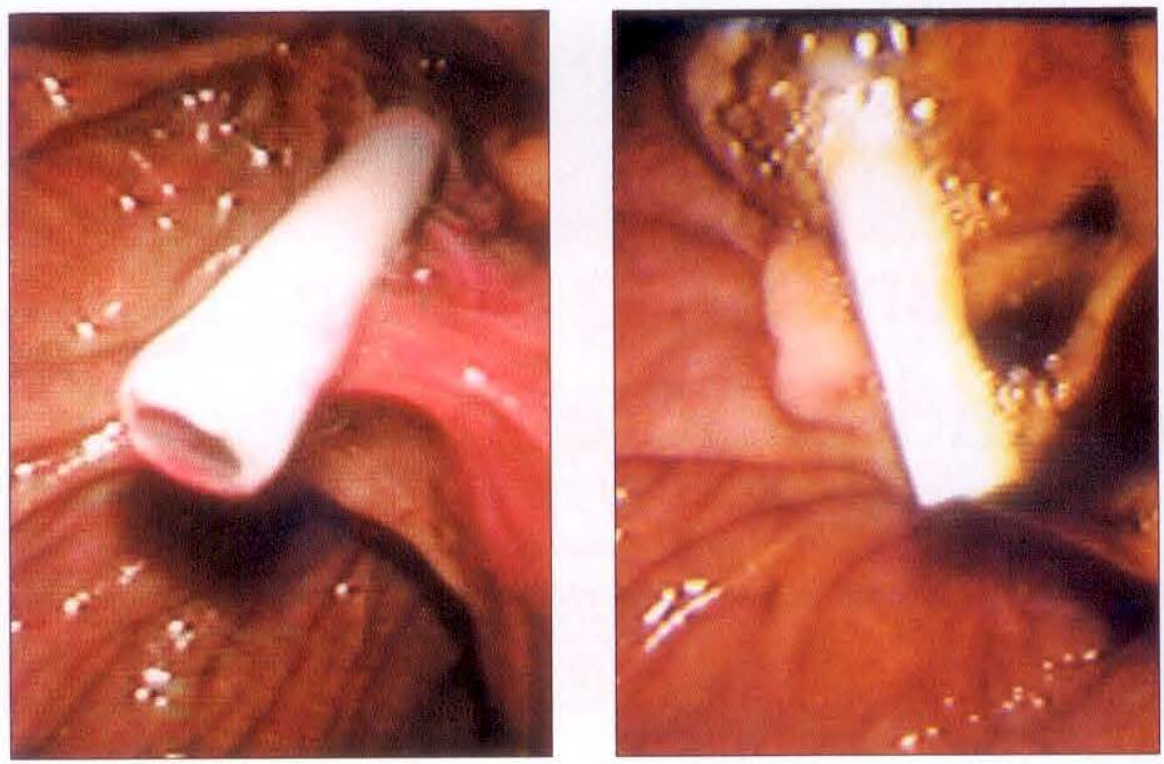

Figure 1) Endoprosthesis in duodenum with good bile flow

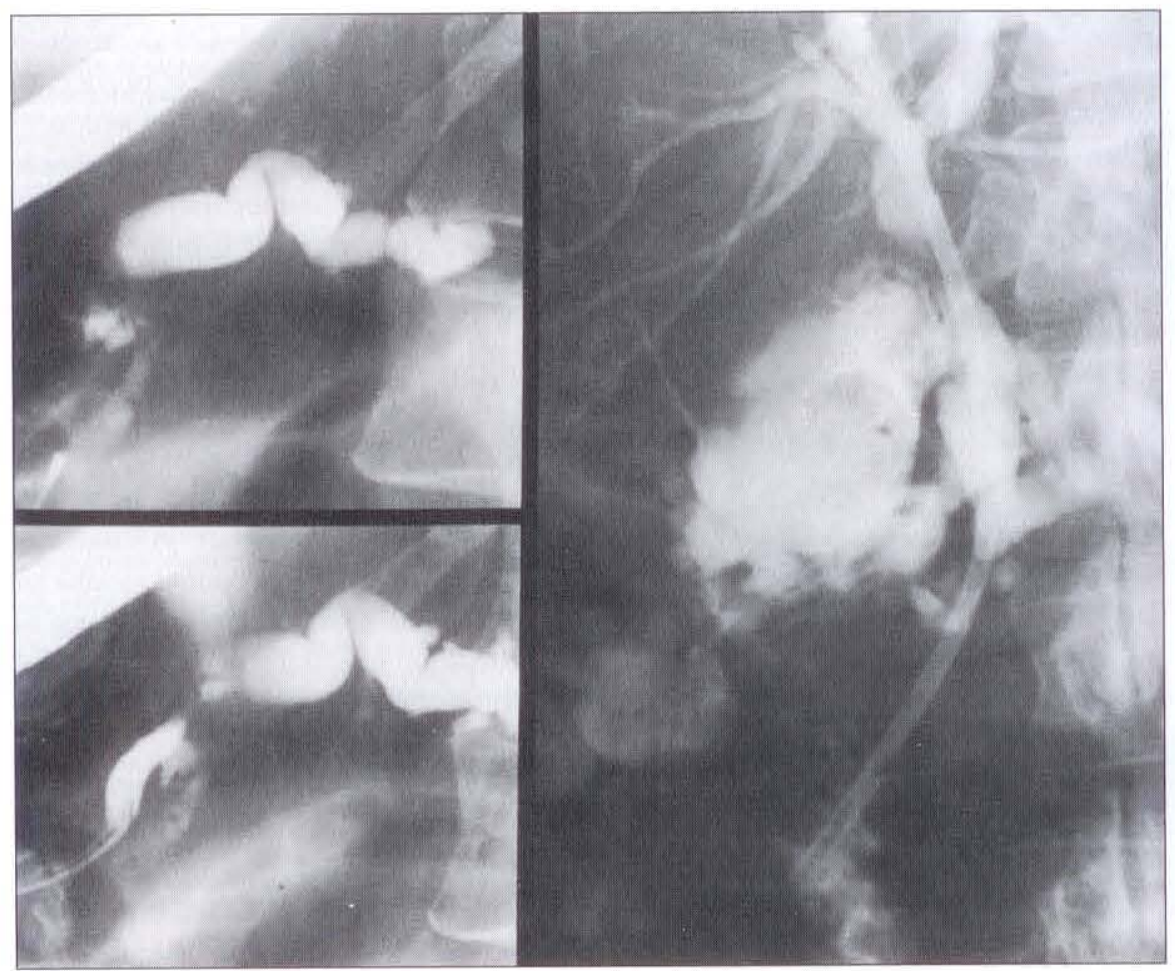

Figure 2) Patient with post cholecystectomy bile leakage due to a distal bile duct obstruction caused by a pancreatic cancer. Left Stricture in pancreatic duct due to pancreatic cancer. Right Bile leakage from cystic stump and biliary endoprosthesis

doscope tip towards the papilla. The right/left knob is in the locked position. Care should be taken to keep the distance between the papilla and the endoscope short. Bowing of the stent in the duodenum makes successful insertion unlikely. When the distal flap reaches the papilla, the assistant pulls the Teflon catheter and wire out as the endoscopist holds the stent in place with the pusher tube. Once the stent is freed from the endoscope about $1 \mathrm{~cm}$ should be protruding from the papilla (Figure 1). After drainage is established endoscopically or under fluoroscopy the endoscope is withdrawn.

Most stents are straight $10 \mathrm{Fg}$. Nine centimetre stents are often used for dis- tal common bile duct strictures, $11 \mathrm{~cm}$ stents for mid common bile duct strictures, $14 \mathrm{~cm}$ stents for bifurcation and $19 \mathrm{~cm}$ stents for intrahepatic strictures.

\section{INDICATIONS IN BENIGN BILIARY LESIONS}

Postoperative bile leakage: Inadvertent damage to the bile duct during surgery can result in biliary-cutaneous or biliary-peritoneal fistulas, or high output from $T$-tubes if present. Inadequate closure of the cystic stump can have the same effect. Traditionally patients have undergone surgical repair, but in the past few years several groups have obtained good results with endoscopic treatment $(3,4)$.

The authors' experience with 55 patients was recently reviewed (4). Patients presented with biliary-cutaneous fistulae, peritonitis, intraabdominal abscess, increasing jaundice, cholangitis or pancreatitis. At ERCP, extravasated contrast flowed from the cystic duct stump (31 patients), the common hepatic duct (six patients), the common bile duct (six patients), a hepatic radical (four patients) and from a surgical anastomosis (one patient). ERCP failed in one patient with a Billroth II. Eventual closure of the leaks or fistulae was achieved in 43 of the 48 patients $(90 \%)$ treated endoscopically. Most closed within 1 to 10 days. Five patients died of persistent sepsis $(10 \%)$. Obstruction distal to the site of bile leakage due to residual stones or strictures was seen in $10 \%$ of the patients (Figure 2).

The purpose of treatment is to facilitate bile flow into the duodenum by eliminating resistance at the sphinc. ter of Oddi. Patients were treated in the following way. If the cystic stump or hepatic radicle leakage was seen without distal obstruction only a sphincteromy was done. If stones were seen in the common bile duct, they were extracted after sphincterotomy. If there was a history of operative biliary trauma, or a stricture was observed, or if all stones could not be extracted, a 10 Fg stent was placed. The prosthesis is helpful in dilating a narrowed area during the healing phase, thereby decreasing the risk of late stricture for- 
mation. In patients in whom a stricture was found one or two stents were placed for about one year. There were no early complications. Late complications included cholangitis in two patients (despite trimonthly stent exchanges) and recurrent stricture after stent removal in one patient.

Endoscopic evaluation and intervention is a valuable tool in the diagnosis and management of postoperative bile leakage and should be performed as soon as it is suspected.

Postoperative and benign biliary strictures: Postoperative biliary strictures occur in 2 to $5 \%$ of patients after biliary tract surgery (5). The choice of drainage procedures includes biliary enteric bypass surgery and percutaneous or endoscopic stenting and balloon dilatation. There are no randomized controlled studies comparing the three options.

Series from major centres reveal good results with endoscopic stents. Geenen et al (6) reported excellent or good response in 25 patients (88\%) who underwent balloon dilation and/or stent placement over a mean follow-up of 48 months. There was no significant morbidity or mortality associated with the procedure. In reviewing the present authors' experience with 70 patients, $83 \%$ had a good or excellent response (7). Seventeen percent had recurrence of the stricture after stent removal over a mean follow-up of 42 months. There was $2.5 \% 30$-day mortality.

These numbers compare very favorably with those from a recent study (8) which showed that expert surgery achieved results in 80 to $90 \%$ of cases over a five-year follow-up. A nonsurgical approach may be the best initial procedure with surgery reserved for those with recurrences.

These patients are usually managed by placing one stent for six weeks (Figure 3), after which two 10 Fg stents are inserted. They are left in place for one year, replaced every three months (or earlier) if cholangitis ensues. They are kept in place for one year. Antibiotics are administered if cholangitis is present or if successful drainage is not obtained. Because of the tight fibrotic nature of the strictures, $21 \%$ of patients require dilation before stent placement.

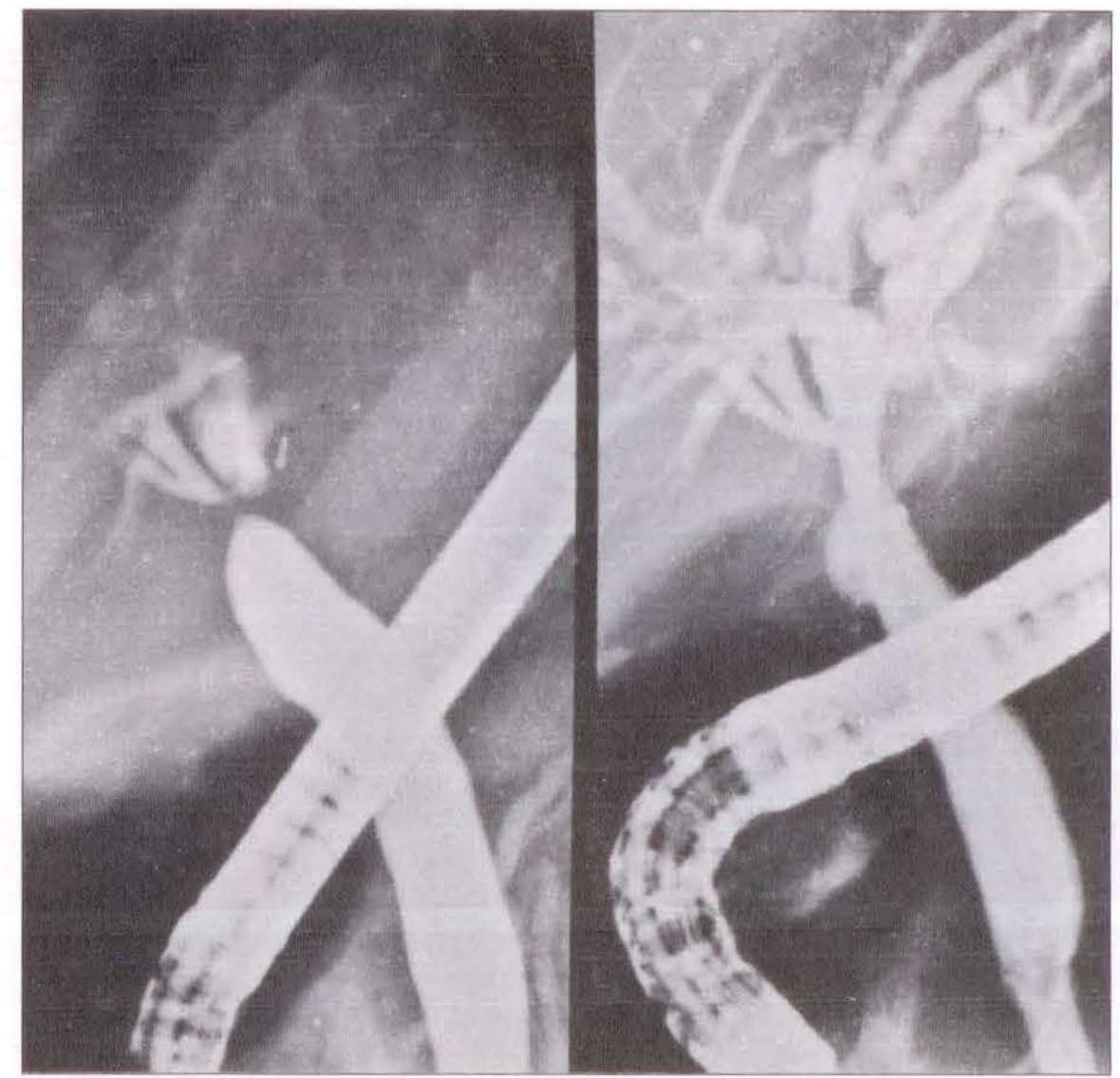

Figure 3) Patient with liver cirrhosis due to a post operative biliary stricture. Left Postoperative stricture at the bifurcation. Right Endoprothesis is inserted for stricture dilation

Balloon catheters ( 4 to $8 \mathrm{~mm}$ outside diameter) or metal tipped dilating catheters can be used. Balloon dilation alone (without stenting) has not been found to be beneficial, by these authors, although others have reported good results with dilation only.

Finally, after removal of the stents, the stricture is considered sufficiently dilated if a $1 \mathrm{~cm}$ balloon can be pulled through easily or if rapid drainage is seen under fluoroscopy.

Other benign strictures can be treated in the same manner but care must be taken to ensure that they are indeed benign. A lack of a tumour 'shelf' or even negative cytology brushings do not rule out malignancy.

Endoscopic biliary drainage is also used for patients with chronic pancreatitis who have intrapancreatic biliary strictures causing jaundice. These strictures are usually longer, smoother and easier to intubate than those caused by pancreatic cancer. The natural history of these strictures is unclear. Biliary drainage provides an adequate temporary measure while the patient undergoes further evaluation. It also serves as an alternative to surgery in high risk patients.

Primary sclerosing cholangitis: Primary sclerosing cholangitis is a chronic fibrosing inflammatory disease of the intra- and extrahepatic bile ducts resulting in areas of strictures and dilations forming the classic 'beading' pattern. Its pathogenesis is unknown but evidence suggests an autoimmune process. Evaluation of endoscopic treatment is hampered by the small numbers of patients reported and the variability of interindividual disease patterns.

The disease can affect intrahepatic, extrahepatic or both ductal systems to varying degrees. Nonetheless, treatment of patients with cholangitis and jaundice who have dominant strictures (classified as major ductal strictures in primary branches of large intra- or extrahepatic ducts) is advocated $(2,9)$. Stones and debris are removed and the 


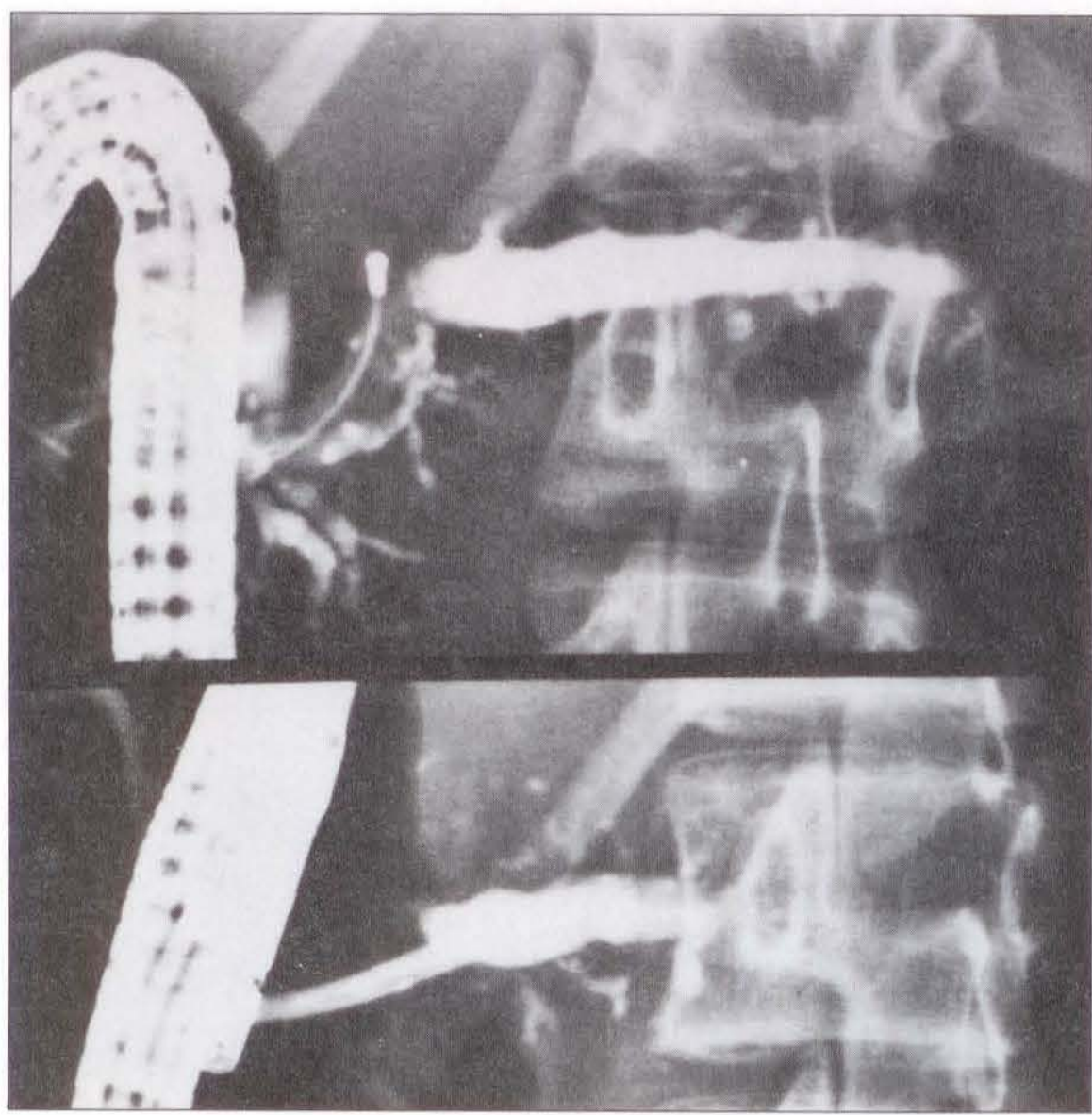

Figure 4) Patient with recurrent pancreatitis and pancreas divisum. Top Highly dilated dorsal pancreatic duct. Bottom Endoprosthesis ( $10 \mathrm{Fg}$ ) is inserted via minor papilla

strictures either dilated with balloons or stented. Follow-up of 35 patients treated with combinations of stents and dilations showed significant improvement in rates of hospitalization for cholangitis and in laboratory data (9). Antibiotics should be given before and for several days after treatment. Nasobiliary drainage should be used if dilation or stent placement is not immediately possible. Follow-up attempts can then be performed safely a few days later. One study found that if adequate dilation could be obtained with Gruntzig balloons or Soehendra dilating catheters, stents should probably not be placed as they appear to increase the risk of subsequent cholangitis (9).

Biliary endoprostheses in gallstone disease: Occasionally very elderly or very high risk patients have common bile duct stones that are either too large or too numerous for endoscopic clearance. Despite the many treatment modalities available, several studies have shown that stenting is a reasonable long term alternative in this sub. group of patients $(10,11)$. One study of 63 patients treated with permanent endoprosthesis reported good results in a one- to five-year follow-up with only 14 patients requiring stent exchange (12). The exchange is not routine, and should be performed only if patients become symptomatic. The stent, if possible, should be $19 \mathrm{~cm}$ long in order that it can be positioned high in the biliary tree so it does not migrate out. lts purpose is to prevent stone impaction and thus cholangitis.

Pancreatic drainage: Because therapeutic endoscopy of the pancreas is technically difficult and chronic pancreatitis is uncommon, most studies have been conducted at the few centres with the necessary expertise. Treatment can consist of pancreatic sphincterotomy, stone extraction, stricture dilation, nasopancreatic drainage or stent placement (13-16) (Figure 4). Studies in- volving a total of 54 patients with chronic pancreatitis in whom a stent was placed in the main duct across a dominant stricture showed improved pain control in $91 \%$ (17). Several other studies have shown decreased signs and symptoms in patients with pancreas divisum who had a stent placed in the dorsal duct. Although the results of stent placement are encouraging there are potential risks, such as inducing further ductal changes, that must be studied (18). Because so many questions remain as to optimal duration of therapy and patient selection, general clinical use of pancreatic stents is not recommended at present.

\section{MALIGNANT BILIARY STRICTURES}

Malignant bile duct obstruction is a disease mainly of the elderly (19). By the time clinical signs and symptoms occur and patients present to physicians, spread to the liver, nodal bed and adjacent vascular structures has frequently occurred (20). Because of the late presentation of the malignancy and the concomitant physiologic dys. function of the elderly, few can undergo curative resection. Palliative surgical intervention has an overall operative mortality of 20 to $30 \%(21,22)$. Surgical intervention, however, offers the only chance of a cure. Therefore, careful consideration for surgical intervention is warranted on an individual basis, taking into consideration the type and extent of the tumour, and a patient's physiological status. For the majority of patients endoscopic therapy offers the best method of palliation. The rationale for palliative intervention is the relief of pruritus, malaise, occasional cholangitis, multiple organ dysfunction and physiological impact of jaundice.

Because of its deleterious effects on multiple organ systems, obstructive jaundice is thought to increase surgical morbidity and mortality. Three randomized studies with percutaneous drainage have not shown benefit (23-25). Whether endoscopic drainage with its lower risk of complications will show any benefits remains to be studied.

Successful drainage rates and complications vary with the site of obstruc. 
TABLE 1

Results of biliary endoprosthesis in 1153 patients (38)

\begin{tabular}{|c|c|c|c|c|c|c|c|}
\hline & $\begin{array}{l}\text { Success } \\
\text { rate }\end{array}$ & $\begin{array}{l}\text { 30-day } \\
\text { mortality }\end{array}$ & Cholangitis & $\begin{array}{l}\text { Bilirubin } \\
\text { decrease }\end{array}$ & Stent clogging & $\begin{array}{l}\text { Duodenal } \\
\text { stenosis }\end{array}$ & $\begin{array}{l}\text { Median } \\
\text { survival }\end{array}$ \\
\hline Bifurcation & $85 \%$ & 23 & $25 \%$ & $86 \%$ & $28 \%$ & $2 \%$ & $95(1$ to 2319$)$ \\
\hline $\begin{array}{l}\text { Gallbladder carcinoma } \\
\text { (biopsy proven) }\end{array}$ & $86 \%$ & 16 & $11 \%$ & $93 \%$ & $40 \%$ & $6 \%$ & $123(3$ to 1255$)$ \\
\hline $\begin{array}{l}\text { Pancreatic } \\
\text { carcinoma }\end{array}$ & $92 \%$ & 11 & $7 \%$ & $97 \%$ & $29 \%$ & $9 \%$ & $149(0$ to 934$)$ \\
\hline Papillary carcinoma & $97 \%$ & 1 & $5 \%$ & $98 \%$ & $53 \%$ & $23 \%$ & 409 ( 12 to 2365$)$ \\
\hline
\end{tabular}

Median survival is in days (range)

tion (Table 1). The management of distal, mid common duct and proximal biliary tree lesions is described.

Distal lesions: Papillary carcinoma is the cause of malignant jaundice in $8 \%$ of cases. The tumour can be seen as a fleshy, friable, exophytic growth, as ulcerated tumours around the papilla, or as a mass behind the papillary opening covered with normal-looking mucosa (26).

Because the tumour has a better prognosis then other biliary tree malignancies (with five-year survival after surgery in some 30 to $50 \%$ of cases) and because almost $25 \%$ will develop duodenal obstruction (27), surgery is the optimal treatment for these patients. Endoscopic drainage is reserved for patients with contraindications to surgery such as extensive metastases or high surgical risk. Because the tumour is frequently very friable, it is preferable to insert a stent without a sphincterotomy although smaller firmer tumours can initially be treated effectively with sphincterotomy only.

A sphincterotomy may be needed to access tissue for biopsy diagnosis. Successful drainage can be achieved in over $95 \%$ of cases with no procedure related mortality and little morbidity. Late complications, such as stent clogging, which result in jaundice, pain or cholangitis are resolved by stent exchange.

Cancer of the pancreatic head is the most frequent cause of malignant distal bile duct obstruction, accounting for more than $50 \%$ of cases (Figure 5) (28). The median age of onset is 70 years. Less then $30 \%$ of tumours are resectable and five-year survival is a dismal $1 \%$. The mortality of palliative bypass surgery has been reported as high as 43 to $59 \%$ in patients with extensive

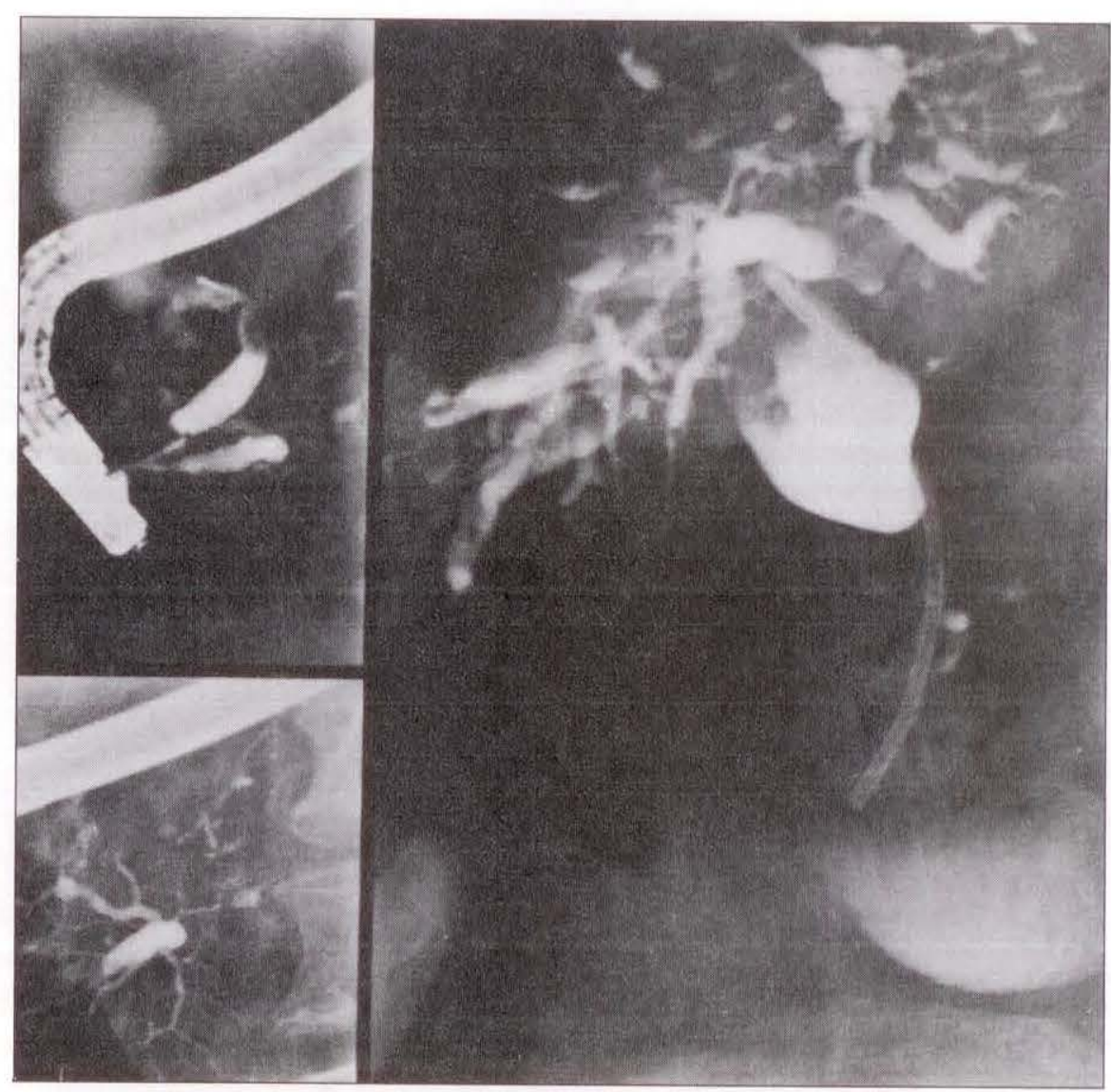

Figure 5) Patient with adenocarcinoma of the pancreas. Left Pancreatic duct obstruction and bile duct obstruction. Right Endoprosthesis in common bile duct with flow of contrast to the duodenum

metastatic disease (29). Three randomized prospective trials of endoscopic versus surgical bypass intervention have been reported (Table 2) (30-32). Patients who had unresectable distal bile duct malignancy but were otherwise operative candidates were randomized to either endoscopic stent placement or surgical bypass. Endoscopic therapy was equally effective in relieving jaundice with less complications and lower 30-day mortality. Survival in both groups was the same, indicating that the advantage lies in the shorter initial hospital stay (two to five days versus the reported three weeks of postoperative hospitalization) and the lower mortality. On the other hand, re-admissions for stent exchange or duodenal obstruction may be intolerable for some patients and quality of life studies of the treatment arms have not been reported.

Tumour growth near the papilla may distort the common bile duct and make cannulation and sphincterotomy difficult. Nonetheless, stent placement is successful in over $90 \%$ of patients 
TABLE 2

Results of three prospective randomized trials comparing endoscopic stenting with surgical bypass for obstructive jaundice (30-32)

\begin{tabular}{|c|c|c|c|c|c|c|}
\hline & \multicolumn{2}{|c|}{ Shepherd et al (30) } & \multicolumn{2}{|c|}{ Andersen et al (31) } & \multicolumn{2}{|c|}{ Dowsett et al (32) } \\
\hline & Stent & Surgery & Stent & Surgery & Stent & Surgery \\
\hline Number of patients & 23 & 25 & 25 & 19 & 101 & 103 \\
\hline Successful drainage & $91 \%$ & $92 \%$ & $96 \%$ & $84 \%$ & $94 \%$ & $91 \%$ \\
\hline Complications & $22 \%$ & $40 \%$ & NA & NA & $10 \%$ & $28 \%{ }^{\dagger}$ \\
\hline 30-day mortality & $9 \%$ & $20 \%$ & NA & NA & $7 \%$ & $17 \%{ }^{\dagger}$ \\
\hline Duodenal bypass & $0 \%$ & $0 \%$ & $0 \%$ & $0 \%$ & $6 \%$ & $1 \%{ }^{\dagger}$ \\
\hline
\end{tabular}

"Mean survival: 'Statistically significant. NA Not available

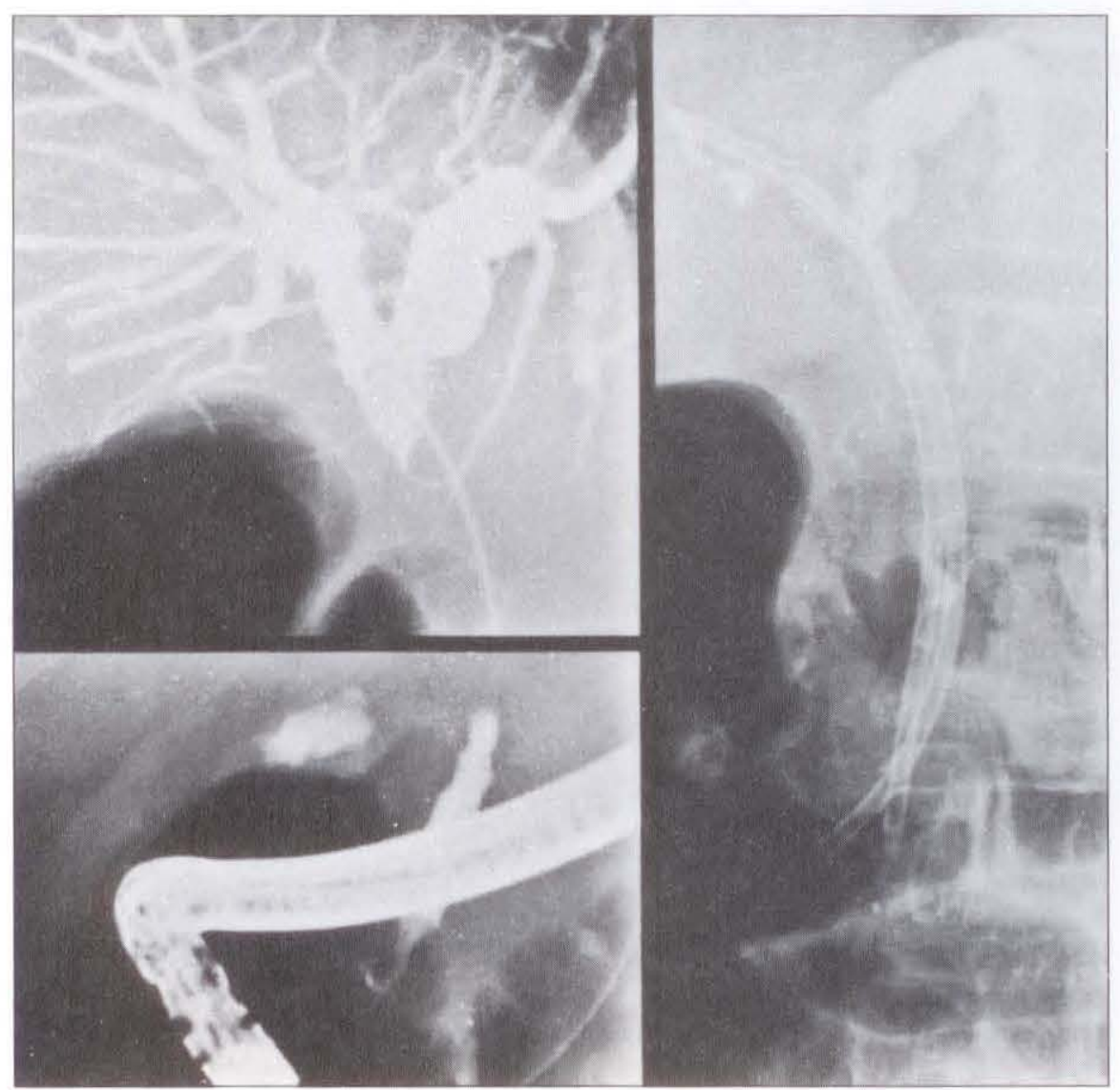

Figure 6) Type I bifurcation stricture. Right Two 10 Fgendoprostheses inserted through the tumour

with procedure related mortality of $2.5 \%, 30$-day mortality of $10 \%$ and average hospital stay of two to five days. Although cases must be judged individually as to the henefit of surgical bypass versus endoscopic drainage, the latter is felt to be the best method in patients without impending duodenal obstruction.

Mid common duct obstruction: Gallbladder carcinoma and cholangiocarcinoma are the more frequent causes of mid duct obstruction; 15 to $20 \%$ of patients with malignant jaundice will have a lesion at this level. By the time jaundice becomes manifest, over 15\% of patients have liver and nodal bed involvement, while less then 15 to $25 \%$ have resectable disease. Palliative surgical procedures have produced mortality rates of 15 to $20 \%$ and do not prolong survival beyond a mean of four to six months. Nearly $25 \%$ of patients undergoing surgical palliations die within 30 days of surgery (33). Indeed, tumour extension beyond the submucosa predicts a poor prognosis.

In the authors' series endoscopic drainage was successful in $84 \%$ of patients. Procedure related mortality was $3.1 \%$ and 30 -day mortality was $14.5 \%$ (33). Overall mean survival of 23 weeks was comparable to that achieved with surgical palliation of advanced disease. Given the dismal outcome of the disease, endoscopic management provides palliation at a lower mortality, morbid. ity and cost than surgical bypass.

Bifurcation tumours: Malignant growths involving the bifurcation may arise from adjacent organs, lymphoma or metastases from the colon or breast. They account for 20 to $25 \%$ of cases with malignant jaundice. This type of malignant obstruction is difficult to treat by any intervention and often requires co-operation between the radiologist, surgeon and gastroenterologist.

Patients with primary hilar bile duct cancer should be evaluated for surgery in hope for a cure. Surgical series note resectability rates of $20 \%$ (34), $22 \%$ (35) and even $47 \%$ (36). A recent review of 499 patients who underwent resections showed an operative mortality of $12 \%$ and a five-year survival of $13 \%$. The median survival was 14 to 18 months. Palliative surgical bypass has an operative mortality of $33 \%$ (34). Cholangitis is a frequent complication of hepaticojejunostomies.

Endoscopic stent placement across these often tortuous and asymmetric strictures is technically demanding (Figure 6). The usual cause of failure is inability to pass a guidewire or dilating 
TABLE 3

Results of endoscopic treatment of hilar lesions by Bismuth classification

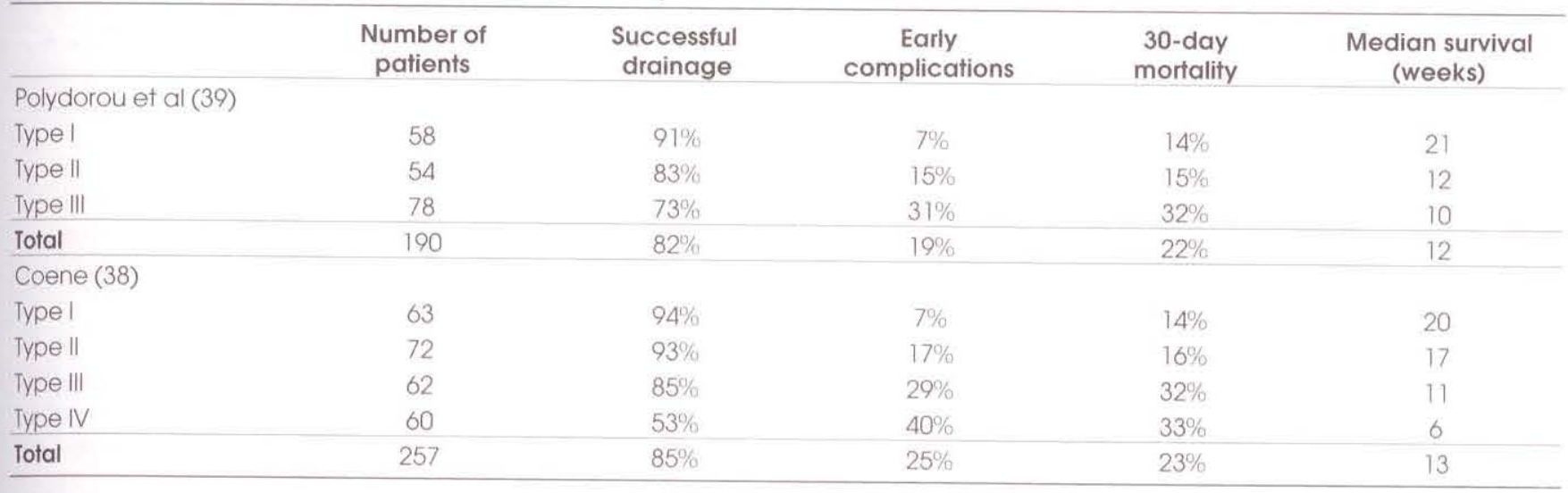

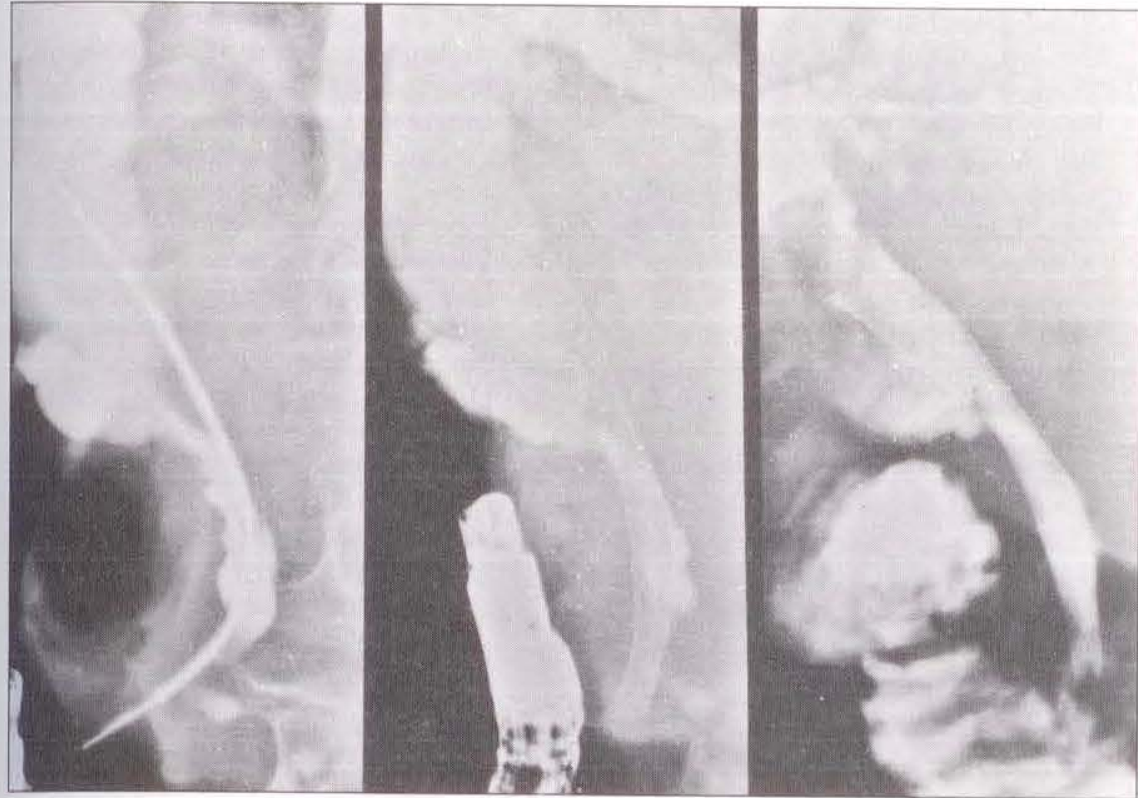

Figure 7) Left The constrained wallstent is inserted through a distal bile duct stricture. Middle The wallstent is completely deployed. Right Optimal flow of contrast throngh the stent

catheter through a stricture. Overall successful drainage rates are 80 to $85 \%$ (37-39). The Bismuth classification is useful in reporting results of intervention. Type I tumours involve the common hepatic duct within $2 \mathrm{~cm}$ of the bifurcation, but not the right and left duct. Type II lesions extend to involve both main hepatic ducts. In Type III tumours, the right, left and intrahepatic ducts are involved. The more extensive the disease (ie, Type III) the higher the morbidity and mortality rates (Table 3). All rates are worse in cases of metastases from distant malignancies. Type III lesions from metastatic disease had successful drainage in $71 \%$ of cases, complications in $71 \%$, 30-day mortal- ity in $42 \%$ and median survival of 1.5 months in one report (40). In patients with extensive intrahepatic strictures the benefit of any intervention is questionable.

The major early complication is cholangitis which has been reported in 7 to $19 \%$ of cases. Although all cases are performed with antibiotic coverage, adequate drainage is the critical element. This may entail more than one attempt at stent placement or a combined percutaneous/endoscopic approach. Controversy exists as to the need to drain all obstructed liver segments. Some do so aggressively (37) but others have obtained good results with just one stent draining at least $25 \%$ of the liver parenchyma (39). A second stent is placed only in those with cholangitis from suspected undrained segments (38).

Early and late complications of endoprosthesis: Early complications occur less than one week after the procedure while late complications can occur from eight days to 15 months after insertion (38). The main complication is clogging which occurs in 21 to $36 \%$ of cases. Patients present with a 'flu-like syndrome, malaise, low grade fever or increasing liver enzymes. If symptoms are not recognized promptly, frank jaundice and cholangitis will ensue. Symptoms respond promptly to stent exchange. Studies on the mechanisms of clogging and possible solutions are ongoing. Self expanding wire-mesh 30 Fg stents are being evaluated with promising initial results (Figure 7) (41).

\section{CONCLUSIONS}

Endoscopic endoprostheses offer a good alternative to surgical intervention, producing low mortality and morbidity rates in many situations. Therefore, an increasing need for these procedures can be expected. In a recent report of the British Society of Gastroenterology this need was calculated as 50 ERCP procedures per 100,000 inhabitants per year, of whom 16 per 100,000 need a biliary drainage procedure (42). Good training of endoscopists and cooperation between interventional radiologists, surgeons and gastroenterologists are prerequisites for optimal treatment of the patient with obstructive jaundice. 


\section{REFERENCES}

1. Soehendra N, Reynders-Frederix V. Palliative bile duct drainage. A new endoscopic method of introducing a transpapillary drain. Endoscopy 1980:12;8-11.

2. Huibregtse K. Endoscopic Biliary and Pancreatic Drainage. New York: Georg Thieme Verlag, 1988.

3. Ponchon T, Gallez JF, Valette PJ, Chavaillon A, Bory R. Endoscopic treatment of biliary tract fistulas. Gastrointest Endosc 1989:35;490-8.

4. Davids PHP, Rauws EAJ, Coene PPLO, Tytgat GNJ, Huibregtse K. Postoperative bile leakage: The endoscopic management. Gut 1992;33:1118-22.

5. Huibregtse K, Katon RM, Tytgat GNJ. Endoscopic treatment of postoperative biliary strictures. Endoscopy 1986:18;133-7.

6. Geenen DJ, Geenen JE, Hogan WJ, et al. Endoscopic therapy for benign bile duct strictures. Gastrointest Endosc 1989:35;367-71.

7. Davids PHP, Rauws EAJ, Coene PPLO, Tytgat GNJ, Huibregtse K. Benign postoperative biliary strictures: Endoscopic management and long-term follow-up. Gastrointest Endosc 1991:37;251-2.

8. Pitt HA, Kauffmann SL, Coleman I, et al. Benign postoperative biliary strictures: Operate or dilate? Ann Surg 1989:210;417-27.

9. Johnson GK, Geenen JE, Venu RP, Schmalz MJ, Hogan WJ. Endoscopic treatment of biliary strictures in sclerosing cholangitis: A larger series and recommendations for treatment. Gastrointest Endosc 1991:37;38-43.

10. Cairns SR, Dias L, Cotton PB, Salmon PR, Russell RCG. Additional endoscopic procedures instead of urgent surgery for retained common bile duct stones. Gut 1989:30;535-40.

11. Lesterhuis W. Non-surgical therapy of common bile duct stones in man. The Netherlands: SDU's-Gravenhage, 1988.

12. Kul ], Kruse A, Rokkjaer M. Large bile duct stones treated by endoscopic biliary drainage. Surgery 1989;105:51-6.

13. Huibregtse K, Schneider B, Vrij AA. Tytgat GNJ. Endoscopic pancreatic drainage in chronic pancreatitis. Gastrointest Endosc 1988:34;9-15.

14. Geenen JE, Rolny P. Endoscopic therapy of acute and chronic pancreatitis. Gastrointest Endosc 1991:37;377-82.

15. Irani SK. Endoscopic management of pancreatic disorders. Gastroenterol Clin North Am 1990:19;975-97.

16. Cremer M, Deviere J, Delhaye M, Baize M, Vandermeeren A. Stenting in severe chronic pancreatitis: Results of medium-term follow-up in seventy-six patients. Endoscopy 1991:23;171-6.

17. Buddick JS, Hogan WJ. Chronic pancreatitis: Selection of patients for endoscopic therapy. Endoscopy 1991;23:155-60.

18. Kozarek RA. Pancreatic stents can induce ductal changes consistent with chronic pancreatitis. Gastrointest Endosc 1990;36:93-5.

19. Cotton PB. Management of malignant bile duct obstruction. J Gastroenterol Hepatol 1990;(Suppl 1):63-77.

20. Huibregtse K, Cheng J. Management of malignant biliary strictures. In: Barkin J, O'Phelan CA, eds. Advanced Therapeutic Endoscopy. New York: Raven Press Ltd, 1990:229-48.

21. Sarr MG, Cameron JL. Surgical palliation of unresectable carcinoma of the pancreas. W J Surg 1984;8:906-18.

22. Warshaw AL, Swanson RS. Pancreatic cancer in 1988. Ann Surg 1988;97:541-53.

23. Hatfield ARW, Tobas R, Terblanche $\mathrm{J}$, et al. Preoperative external biliary drainage in obstructive jaundice: $\mathrm{A}$ prospective controlled clinical trial. Lancet 1982;ii:896-8.

24. McPherson GAD, Benjamin IS, Hodgson HJF, et al. Preoperative percutaneous transhepatic biliary drainage: The results of a controlled trial. Br J Surg 1984;71:371-5.

25. Pitt HA, Gomes AS, Lois JF, et al. Does preoperative percutaneous biliary drainage reduce operative risk or increase hospital cost. Ann Surg 1985;201:545-53.

26. Huibregtse K, Tytgat GNJ. Carcinoma of the ampulla of Vater: The endoscopic approach. Endoscopy 1988;20;223-6.

27. Huibregtse K, Schneider B, Rauws E, et al. Carcinoma of the ampulla of Vater: the role of endoscopic drainage. Surg Endosc 1987;1:79-82.

28. Huibregtse K. Non-operative palliation of pancreatic cancer. Ballière's Clinical Gastroenterology 1990;4:995-1004.

29. Connolly MM, Dawson PJ, Melassi F, et al. Survival in 1001 patients with carcinoma of the pancreas. Ann Surg 1987;206:397-400

30. Shepherd HA, Royle G, Ross APR, Diba A, Arthur M, Colin-Jones D. Endoscopic biliary endoprosthesis in the palliation of malignant obstruction of the distal common bile duct: A randomised trial. Br J Surg 1988:75;1166-8

31. Andersen JR, Sorensen SM, Kruse A, Rokkjaer M. Randomised trial of endoscopic endoprosthesis versus operative bypass in malignant obstructive jaundice. Gut 1989:30;1132-5.

32. Dowsett JF, Russell RCG, Hatfield ARW, et al. Malignant obstructive jaundice; a prospective randomised trial of surgery versus endoscopic stenting. Gastroenterology 1989;96:Al28

33. Huibregtse K, Schneider B, Coene PP, et al. Endoscopic palliation of jaundice in gallbladder cancer. Surg Endosc 1987;1:143-6.

34. Blumgart LH, Benjamin IJ, Hadjis NS, et al. Surgical approaches to cholangiocarcinoma at confluence of hepatic ducts. Lancet 1984;i;66-9.

35. Langer JC, Langer $B$, Taylor BR, et al. Carcinoma of the extrahepatic bile ducts: results of an aggressive surgical approach. Surgery 1985;98:752-9.

36. Tompkins RK, Thomas D, Wile A, Longmire WP. Prognostic factors in bile duct carcinoma. An analysis of 96 cases. Ann Surg 1981;194:447-57.

37. Deviere J, Baize M, de Toeuf J, Cremer M. Long-term follow-up of patients with hilar malignant stricture treated by endoscopic internal biliary drainage. Gastrointest Endosc 1988:34;95-101.

38. Coene PPLO. Endoscopic biliary stenting: Mechanisms and possible solutions of the clogging phenomenon. Netherlands: Krips Repro, Meppel, 1990.

39. Polydorou AA, Cairns SR, Dowsett JF, et al. Palliation of proximal malignant biliary obstruction by endoscopic endoprosthesis insertion. Gut 1991:32;685-90.

40. Dowsett JF, Polydorou A, Vaira D, Cairns SR, Croker J, Cotton PB. Endoscopic stenting for malignant biliary obstruction: How good really? A review of 641 consecutive patients. Gut 1988;29:A1458.

41. Huibregtse K, Carr-Locke DL, Cremer $\mathrm{M}$, et al. Biliary stent occlusion - a solved problem with self expanding metal stents. Endoscopy 1992;24:391-4.

42. Gear MWL, Dent NA, Colin-Jones DG, Lennard-Jones JH, Colley JRT. Future needs for ERCP: Incidence of conditions leading to bile duct obstruction and requirements for diagnostic and therapeutic biliary procedures. Gut 1990:31;1150-5. 


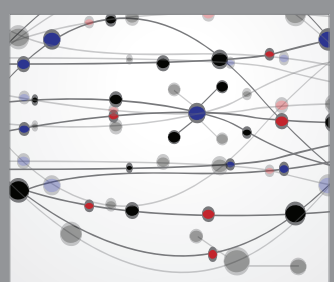

The Scientific World Journal
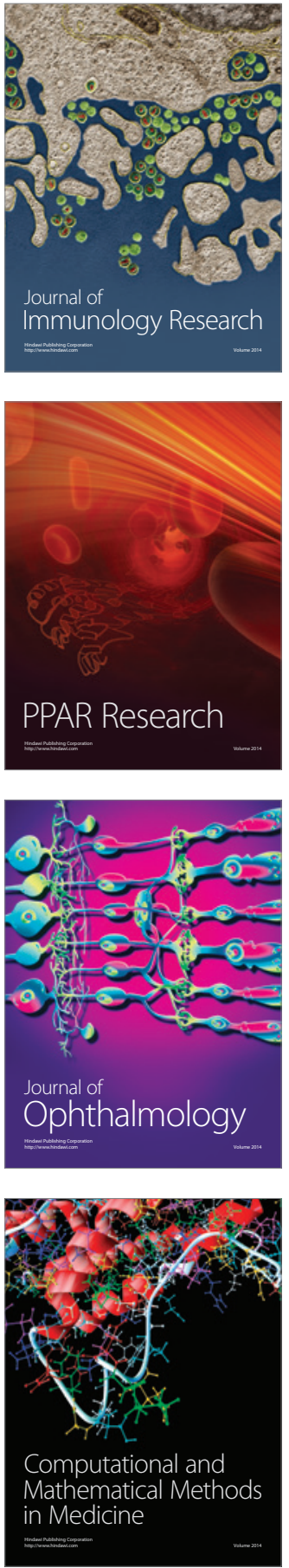

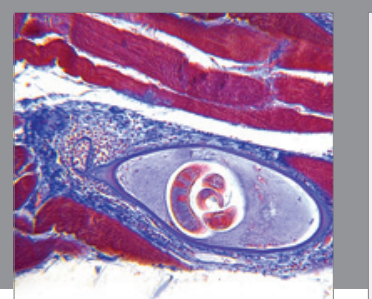

Gastroenterology Research and Practice

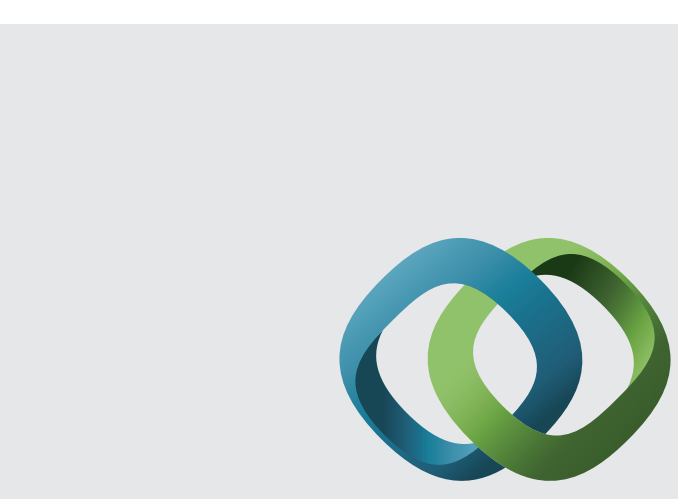

\section{Hindawi}

Submit your manuscripts at

http://www.hindawi.com
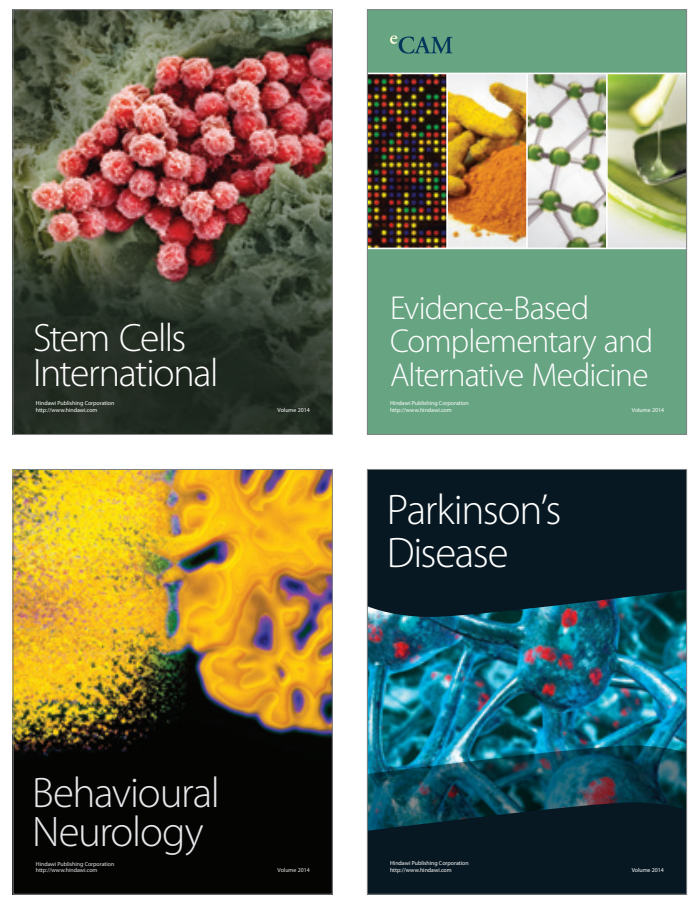
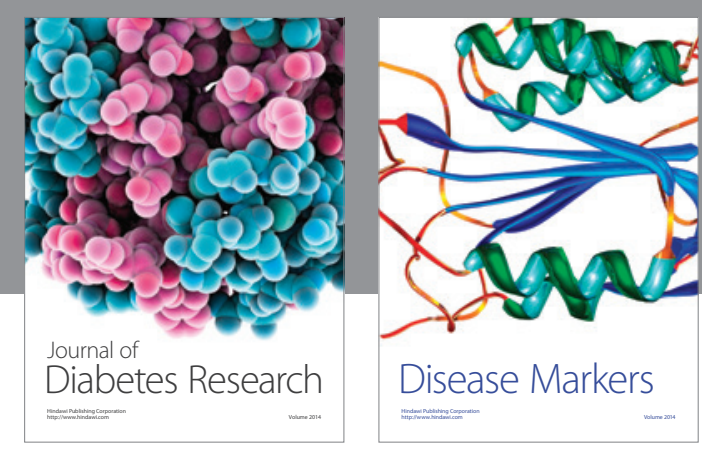

Disease Markers
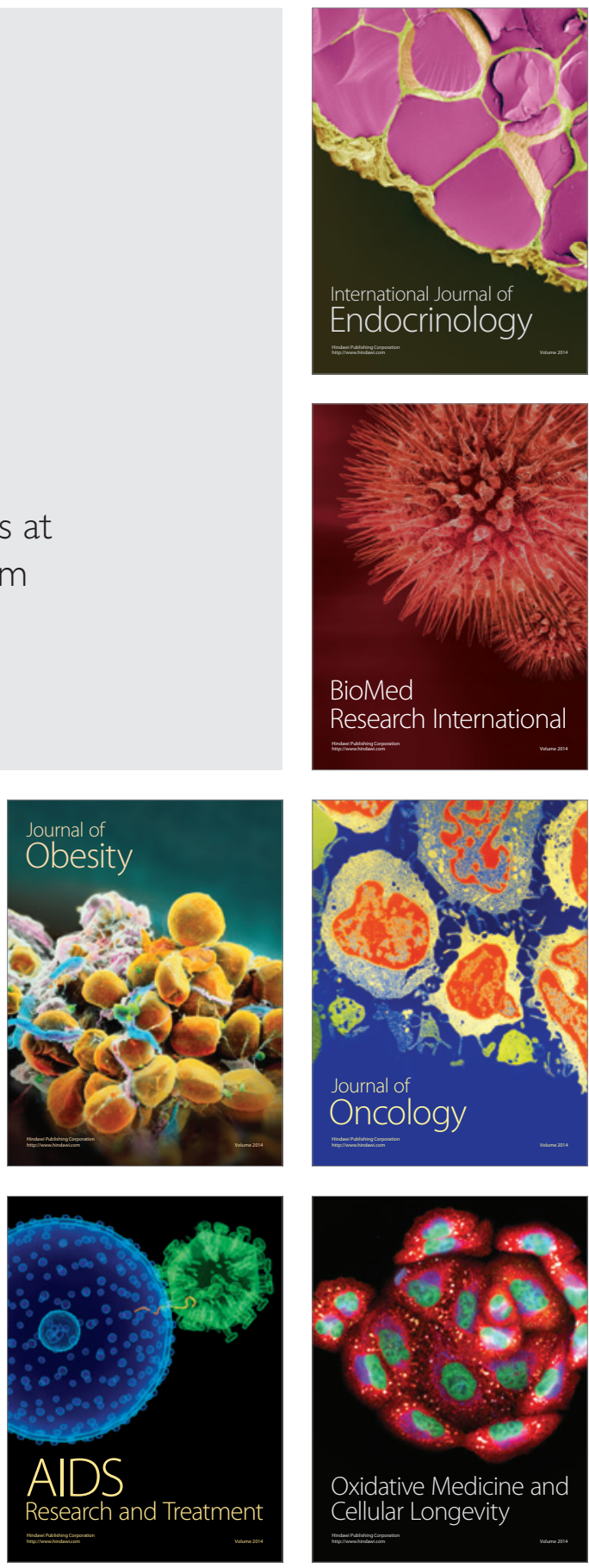